\title{
Multi-Occurrence of Twenty Mycotoxinsin Pasta and a Risk Assessment in the Moroccan Population
}

\author{
Youssef Bouafifssa ${ }^{1}$, Lara Manyes $\left.{ }^{2}{ }^{(}\right)$, Mohamed Rahouti ${ }^{1}\left(\mathbb{D}\right.$, Jordi Mañes ${ }^{2}{ }^{(1)}$, \\ Houda Berrada ${ }^{2, * \mathbb{C}}$, Abdellah Zinedine ${ }^{3}$ and Mónica Fernández-Franzón ${ }^{2}$ \\ 1 Department of Biology, Faculty of Sciences, University Mohammed V Agdal, Avenue Ibn Batouta, \\ Rabat 10010, Morocco; youssef1238@gmail.com (Y.B.); medrahouti@gmail.com (M.R.) \\ 2 Laboratory of Food Chemistry and Toxicology, Faculty of Pharmacy, University of València, \\ Vicent Andrés Estelléss/n, 46100 Burjassot, Spain; lara.manyes@uv.es (L.M.); jordi.manes@uv.es (J.M.); \\ monica.fernandez@uv.es (M.F.-F.) \\ 3 Team of Applied Microbiology and Biotechnologies, Laboratory of Marine Biotechnologies and \\ Environment (BIOMARE), Faculty of Sciences, Chouaiib Doukkali University, El Jadida 24000, Morocco; \\ zinedineab@yahoo.fr \\ * Correspondence: houda.berrada@uv.es
}

Received: 30 September 2018; Accepted: 23 October 2018; Published: 26 October 2018

\begin{abstract}
In the present study, the multi-occurrence of twenty (20) mycotoxins in pasta samples consumed in Morocco was assessed. For this, a modified Quick, Easy, Cheap Effective, Rugged, and Safe method was validated. The mycotoxins studied were identified and quantified by liquid chromatography-tandem mass spectrometry (LC-MS/MS) and gas chromatography-tandem mass spectrometry (GC-MS/MS). The validated method was applied to one hundred and six $(n=106)$ pasta samples purchased from several areas in the country. The analytical results showed that 99 out of 106 total samples (93.4\%) were contaminated with at least one mycotoxin. Nine mycotoxins (Aflatoxin B1, Enniatin B, Enniatin B1, Enniatin A1, Zearalenone, Deoxynivalenol, 3-Acetyl-Deoxynivalenol, T-2, and HT-2 toxins) were present in the pasta samples. Enniatin B and Enniatin B1 were the predominant mycotoxins. The Zearalenone, Deoxynivalenol, HT-2, and T-2 toxins were present in $51.8 \%, 43.5 \%$, $34.9 \%$, and $16 \%$ of samples, respectively. Aflatoxin B1 was detected in only 2 samples. Risk exposure assessment concluded that mycotoxin levels found in pasta do not pose a significant human health risk for the Moroccan population. This is the first paper drafted on the multi-occurrence of mycotoxins in pasta from this country.
\end{abstract}

Keywords: mycotoxins; occurrence; QuEChERS; pasta; risk assessment

Key Contribution: The presence of 20 mycotoxins in pasta from Morocco was evaluated by both liquid and gas chromatography coupled to mass spectrometry in tandem; at least one mycotoxin was detected in $93.4 \%$ of the samples being enniatins the most frequently identified mycotoxins.

\section{Introduction}

Pasta is a cereal-based food produced and consumed all over the world. It is made from rice flour in Asia, from maize flour in South America, and from wheat in Northern, Eastern Europe, and Africa, but in general, pasta is made of durum wheat semolina. According to the International Association of Pasta, about 13.6 million tons of pasta are produced worldwide by more than 45 producer countries [1]. Pasta plays an important role in human nutrition and is present on a daily basis. It is easy to prepare and has many advantages for consumers such as having a low price, excellent nutritional value, multiple ways of preparation, and the possibility of being stored for a long time period after production [2]. 
Moroccan population is one of the largest consumers of cereals and cereal products. Indeed, 6 million tons of cereals are consumed each year and the average consumption of cereals is $200 \mathrm{~kg}$ per capita. Pasta constitutes one of the most important cereal-based products of the Moroccan economy since the production of pasta in the country reached about 85,000 tons in 2009 [3].

Pasta can be contaminated with mycotoxins that are natural food and feed contaminants, produced mainly by the molds of the genera Aspergillus, Penicillium, and Fusarium. Since pasta is very commonly used in the human diet, mycotoxins are of concern due to their potentially harmful effects. Mycotoxins are currently considered the most important chronic dietary risk factor, higher than synthetic contaminants, food additives, or pesticide residues [4]. Aflatoxin B1 (AFB1) and other naturally occurring aflatoxins (AFs) have been classified as group 1 human carcinogens; ochratoxin A (OTA) and fumonisins are classified in group 2B as possible human carcinogens [5]. Monitoring programs indicate that mycotoxin contamination is a worldwide problem [6] since it causes economic losses, both for the grain and for the marketing of foods and feeds, so it is a potential threat to animal and human health [7]. The quality and safety of the final product depend on the raw materials, the type of product processing, and the conditions used in pasta preparation $[8,9]$. Indeed, the technological process of producing pasta and pasta related products (thermal treatment and drying processes) will not eliminate all the microorganisms such as molds producing mycotoxins, or mycotoxins. In addition, during the production process, some microorganisms or mycotoxins could contaminate the pasta [10].

Several countries have set strict regulations about the maximum limits (ML) for mycotoxins in food commodities. The European Union (EU) has established the ML at 2 and $4 \mu \mathrm{g} \mathrm{kg}^{-1}$ for aflatoxin B1 (AFB1) and total aflatoxins (AFTs), respectively, in cereals and cereals products. The ML of Fusarium mycotoxins such as Deoxynivalenol (DON), Zearalenone (ZEA), and Fumonisins are set from 200 to $1750 \mu \mathrm{g} \mathrm{kg}^{-1}$ in cereals and cereal-based products; however, an ML of $25 \mu \mathrm{g} \mathrm{kg}{ }^{-1}$ for the sum of the toxins T-2 and HT-2 is established in pasta [11,12]. Recently, new regulations have been adopted by Moroccan authorities to set the maximum permissible limits for mycotoxins in foodstuffs intended for human consumption. The ML of AFB1 and AFTs are set at 2 and $4 \mu \mathrm{g} \mathrm{kg}^{-1}$ in cereals and cereal-based products, respectively. The ML of OTA is established at 5 and $3 \mu \mathrm{g} \mathrm{kg}{ }^{-1}$ in raw cereals and cereal-based products, respectively. The ML of DON in raw corn and baby foods are set at 1750 and $200 \mu \mathrm{g} \mathrm{kg}{ }^{-1}$, respectively. Finally, The ML of ZEA in raw corn and baby foods are established at 350 and $20 \mu \mathrm{g} \mathrm{kg}{ }^{-1}$, respectively [13]. The presence of mycotoxins in cereals and cereal-based products from Morocco was already reviewed [14], however, until now, no information is available on the multi-mycotoxin occurrence in pasta commercialized in the country.

The QuEChERS (acronym of Quick, Easy, Cheap, Effective, Rugged, and Safe) method was originally developed for the determination of pesticides in vegetables. However, it has been undergoing modifications since its first application in terms of reagents, proportions, and cleanup depending on the analytes and matrices until it reaches the current application for satisfactory mycotoxin extractions. The proposed procedure evaluates mycotoxins QuEChERS extraction from pasta by avoiding the cleanup step.

Recently, increased efforts have been made to perform and develop analytical methods for the detection of low levels of mycotoxins in cereal and derivatives samples, and for the simultaneous analysis of different mycotoxins by using both liquid chromatography-tandem mass spectrometry (LC-MS/MS) and gas chromatography-tandem mass spectrometry (GC-MS/MS) [15,16].

The aims of this work were the development and the validation of a QuEChERS extraction procedure for the analysis of twenty (20) mycotoxins (four Aflatoxins, four Enniatins, three Fumonisins, Beauvericin, and Zearalenone, Nivalenol, Deoxynivalenol, Fusarenon X, 15-acetyldeoxynivalenol, and 3-acetyldeoxynivalenol, T-2, and HT-2) by LC-MS/MS and GC/MS/MS. The validated method was then applied to pasta samples collected in different cities in Morocco for mycotoxin analysis and the estimation of the potential contribution to the dietary exposure of the Moroccan consumers. 


\section{Results and Discussion}

\subsection{Method Validation}

The extraction procedure used in this investigation was derived from the method previously applied in our laboratory for the multi-mycotoxin presence in couscous and wheat semolina samples detected by LC-MS/MS [17] and GC-MS/MS [18], respectively. As some Fusarium mycotoxins (FUS X, DON, HT-2, T-2, NIV, 15-ADON and 3-ADON) provided better sensitivity by GC-MS/MS than LC-MS/MS, both techniques were used in this research. However, a new validation of this method was required due to the matrix investigated (pasta) and the greater number (twenty) of mycotoxins analyzed. Tables 1 and 2 show the validation parameters obtained.

Table 1. The sensitivity, recovery, linearity, and matrix effects using the liquid chromatography-tandem mass spectrometry (LC-MS/MS) analytical method.

\begin{tabular}{|c|c|c|c|c|c|c|c|c|}
\hline \multirow[b]{2}{*}{ Mycotoxin } & \multirow{2}{*}{$\begin{array}{c}\text { LOD } \\
\mu \mathrm{g} \mathrm{kg}^{-1}\end{array}$} & \multicolumn{3}{|c|}{ Mean Recovery (\%) } & \multirow[b]{2}{*}{$\begin{array}{l}\text { Intra-Day } \\
\text { (RSD\%) }\end{array}$} & \multirow[b]{2}{*}{$\begin{array}{c}\text { Inter-Day } \\
\text { (RSD\%) }\end{array}$} & \multirow[b]{2}{*}{$\begin{array}{c}\text { Matrix Effects } \\
\text { SSE (\%) }\end{array}$} & \multirow[b]{2}{*}{$\mathbf{r}^{2}$} \\
\hline & & $\begin{array}{c}25 \\
\mu g \mathrm{~kg}^{-1}\end{array}$ & $\begin{array}{c}50 \\
\mu g k^{-1}\end{array}$ & $\begin{array}{c}100 \\
\mu \mathrm{g} \mathrm{kg}^{-1}\end{array}$ & & & & \\
\hline AFB1 & 0.01 & $108 \pm 19$ & $114 \pm 8$ & $78 \pm 12$ & 11 & 19 & 51 & 0.9914 \\
\hline AFB2 & 0.5 & $60 \pm 17$ & $71 \pm 12$ & $94 \pm 11$ & 8 & 17 & 45 & 0.9983 \\
\hline AFG1 & 0.03 & $59 \pm 18$ & $65 \pm 11$ & $93 \pm 11$ & 12 & 18 & 34 & 0.9935 \\
\hline AFG2 & 0.02 & $80 \pm 12$ & $63 \pm 10$ & $87 \pm 12$ & 6 & 12 & 64 & 0.9648 \\
\hline ENA & 0.025 & $117 \pm 16$ & $92 \pm 8$ & $86 \pm 9$ & 10 & 16 & 69 & 0.9952 \\
\hline ENA1 & 0.025 & $112 \pm 15$ & $83 \pm 11$ & $86 \pm 10$ & 11 & 15 & 67 & 0.9890 \\
\hline ENB & 0.03 & $96 \pm 10$ & $102 \pm 9$ & $116 \pm 12$ & 8 & 10 & 62 & 0.9910 \\
\hline ENB1 & 0.015 & $65 \pm 11$ & $64 \pm 10$ & $63 \pm 18$ & 6 & 16 & 27 & 0.9932 \\
\hline FB1 & 3 & $60 \pm 10$ & $67 \pm 12$ & $64 \pm 17$ & 6 & 12 & 55 & 0.9846 \\
\hline FB2 & 3 & $86 \pm 13$ & $47 \pm 16$ & $61 \pm 17$ & 8 & 19 & 58 & 0.9948 \\
\hline FB3 & 10 & $86 \pm 15$ & $67 \pm 17$ & $61 \pm 15$ & 11 & 13 & 58 & 0.9949 \\
\hline BEA & 1 & $63 \pm 14$ & $60 \pm 15$ & $64 \pm 17$ & 6 & 12 & 66 & 0.9920 \\
\hline ZEA & 0.5 & $103 \pm 12$ & $105 \pm 11$ & $98 \pm 13$ & 8 & 14 & 71 & 0.9860 \\
\hline
\end{tabular}

LOD: limit of detection; RSD: relative standard deviation; SSE: signal suppression/enhancement; $r^{2}$ : regression coefficient.

Table 2. The linearity, recovery, and limit of detection and quantification (LOD/LOQ) using the gas chromatography-tandem mass spectrometry (GC-MS/MS) analytical method.

\begin{tabular}{|c|c|c|c|c|c|c|c|c|}
\hline \multirow[t]{2}{*}{ Mycotoxins } & \multirow{2}{*}{$\mathbf{r}^{2}$} & \multirow{2}{*}{$\begin{array}{c}\text { LOD } \\
\left(\mu \mathrm{kg}^{-1}\right)\end{array}$} & \multirow{2}{*}{$\begin{array}{c}\text { LOQ } \\
\left(\mu \mathrm{kg}^{-1}\right)\end{array}$} & \multicolumn{3}{|c|}{$\begin{array}{c}\text { Recoveries }(\%) \\
\text { Spiking Levels }\left(\mu \mathrm{g} \mathrm{kg}^{-1}\right)\end{array}$} & \multirow{2}{*}{$\begin{array}{l}\text { Intra-Day } \\
\text { (RSD\%) }\end{array}$} & \multirow{2}{*}{$\begin{array}{r}\text { Inter-Day } \\
\text { (R SD\%) }\end{array}$} \\
\hline & & & & 25 & 50 & 100 & & \\
\hline DON & 0.9993 & 0.5 & 1 & $85 \pm 16$ & $89 \pm 11$ & $86 \pm 8$ & 7 & 11 \\
\hline 3-ADON & 0.9998 & 1 & 3 & $95 \pm 11$ & $72 \pm 11$ & $62 \pm 12$ & 9 & 11 \\
\hline 15-ADON & 0.9966 & 1 & 3 & $69 \pm 12$ & $69 \pm 15$ & $62 \pm 21$ & 13 & 15 \\
\hline NIV & 0.9972 & 1 & 2.5 & $97 \pm 4$ & $86 \pm 14$ & $65 \pm 9$ & 2 & 14 \\
\hline $\mathrm{T}-2$ & 0.9993 & 2 & 5 & $80 \pm 11$ & $69 \pm 16$ & $62 \pm 14$ & 5 & 20 \\
\hline HT-2 & 0.9885 & 2.5 & 5 & $69 \pm 10$ & $68 \pm 9$ & $81 \pm 11$ & 15 & 19 \\
\hline FUS $\mathrm{X}$ & 0.9429 & 5 & 10 & $84 \pm 9$ & $73 \pm 12$ & $67 \pm 20$ & 10 & 12 \\
\hline
\end{tabular}

For the LC-MS/MS analysis, LODs for the 13 mycotoxins ranged from 0.01 to $10 \mu \mathrm{gg}^{-1}$. The intra-day and inter-day precision were lower than $12 \%$ and $19 \%$ respectively for all studied compounds (Table 1). Recoveries ranged from 60\% for FB1 and BEA to 117\% for ENA, except for FB2. Correlation coefficients $\left(\mathrm{r}^{2}\right)$ from the matrix-matched the calibration curve is shown in Table 1. As matrix effect was observed for the studied mycotoxins, for the reliable quantization, relative matrix calibration was essential to compensate matrix effect. For GC-MS/MS analysis, limits of quantification (LOQ) were lower than $10 \mu \mathrm{g} \mathrm{kg}^{-1}$ for all the studied mycotoxins (Table 2). The intra-day and inter-day precision were lower than 15\% and 20\%, respectively, for all studied compounds. All recoveries were higher than $60 \%$. Matrix-matched calibration curves were built by spiking blank samples with 
selected mycotoxins before extraction. These results were mainly in a permitted range by Commission Regulation (EC) No. 401/2006.

\subsection{Global Occurrence of Mycotoxins in Pasta}

The presence of mycotoxins in the global samples is summarized in Table 3. Ninety nine (99) out of 106 total samples (93.4\%) were found contaminated with at least one mycotoxin. In total, 9 out the 20 studied mycotoxins were present in the pasta samples; the mycotoxins found were AFB1, the three enniatins (ENB, ENB1, and ENA); ZEA, DON, and 3-ADON; and, finally, the T-2 and HT-2 toxins.

The other mycotoxins studied were below the quantification limits. To our knowledge, this paper describes, for the first time, the multi-presence and the risk assessment of mycotoxins in pasta consumed in Morocco. Figure 1 shows the LC-MS/MS chromatograms for two samples of pasta naturally contaminated with ENB1 $\left(1 \mu \mathrm{g} \mathrm{kg}^{-1}\right)$ and ENB $\left(1.2 \mu \mathrm{g} \mathrm{kg}^{-1}\right)$. Figure 2 shows a chromatogram of a pasta sample with the co-occurrence of five mycotoxins (DON, AFB1, ZEA, ENB1, and ENB).

\subsubsection{The Occurrence of AFB1}

AFB1 was present in only 2 pasta samples, one from Rabat $\left(0.01 \mu \mathrm{g} \mathrm{kg}^{-1}\right)$ and another one from Agadir $\left(0.25 \mu \mathrm{g} \mathrm{kg}^{-1}\right)$. However, AFB1 levels were below the Moroccan [13] and EU regulatory limits [11]. None of the other aflatoxins (AFB2, AFG1, and AFG2) were detected in any pasta samples. In a recent investigation from Morocco, it was reported that one corn couscous semolina was found contaminated with a high level of AFB1 $\left(31.1 \mu \mathrm{g} \mathrm{kg}^{-1}\right)$ and this sample contained a huge amount $\left(50.7 \mu \mathrm{g} \mathrm{kg}^{-1}\right)$ of the total aflatoxins [17].

\subsubsection{The Occurrence of ZEA}

ZEA was present in 55 out of 106 samples (51.8\%). All samples analyzed in this survey were below the maximum level $\left(75 \mu \mathrm{g} \mathrm{kg}^{-1}\right)$ of ZEA set by the EU regulatory limits in cereal and derivatives [12]. Nevertheless, up until now, no maximum limits of ZEA are in force in cereal products by Moroccan regulation adopted recently in 2016. Concerning the frequencies of contamination of pasta samples by origin, it has been observed that high contamination frequencies were found in samples from Agadir $(81.8 \%)$, Tanger $(80 \%)$, and Casablanca $(76.5 \%)$. ZEA is a mycotoxin produced by the Fusarium species. Fungi of the genus Fusarium infect cereals before their harvest in the field. For comparison, a study carried out in Germany reported the ZEA occurrence in a total of 99 cereal samples (41 samples of wheat, 17 of oats, and 41 of corn) [19]. The authors reported that the incidences of ZEA were $63 \%$, $24 \%$, and $85 \%$, respectively, and the mean concentrations were 15,21 , and $48 \mu \mathrm{g} \mathrm{kg}^{-1}$, respectively. Another study conducted in Egypt showed that ZEA was detected in some samples of wheat $(40 \%)$, the levels of contamination ranged between 0.53 and $2.5 \mu \mathrm{g} \mathrm{kg}^{-1}$ [20]. 
Table 3. The multi-mycotoxin occurrence in the analyzed pasta samples.

\begin{tabular}{|c|c|c|c|c|c|c|c|c|c|c|c|c|c|c|c|c|}
\hline \multirow[b]{2}{*}{ Mycotoxin } & \multicolumn{2}{|c|}{ Agadir $(n=11)$} & \multicolumn{2}{|c|}{ Casablanca $(n=17)$} & \multicolumn{2}{|c|}{ Fes $(n=11)$} & \multicolumn{2}{|c|}{ Tanger $(n=10)$} & \multicolumn{2}{|c|}{ Rabat $(n=20)$} & \multicolumn{2}{|c|}{ Sale $(n=12)$} & \multicolumn{2}{|c|}{ Kenitra $(n=15)$} & \multicolumn{2}{|c|}{ Temara $(n=10)$} \\
\hline & $\begin{array}{l}\text { Positive } \\
\text { Samples }\end{array}$ & $\begin{array}{c}\text { Range } \\
\left(\mu \mathrm{g} \mathrm{kg}^{-1}\right)\end{array}$ & $\begin{array}{l}\text { Positive } \\
\text { Samples }\end{array}$ & $\begin{array}{c}\begin{array}{c}\text { Range } \\
\left(\mathrm{\mu g} \mathrm{kg}^{-1}\right)\end{array} \\
\end{array}$ & $\begin{array}{l}\text { Positive } \\
\text { Samples }\end{array}$ & $\begin{array}{c}\text { Range } \\
\left(\mu \mathrm{g} \mathrm{kg}^{-1}\right)\end{array}$ & $\begin{array}{l}\text { Positive } \\
\text { Samples }\end{array}$ & $\begin{array}{c}\begin{array}{c}\text { Range } \\
\left(\mathrm{\mu g} \mathrm{kg}^{-1}\right)\end{array} \\
\end{array}$ & $\begin{array}{l}\text { Positive } \\
\text { Samples }\end{array}$ & $\begin{array}{c}\text { Range } \\
\left(\mu \mathrm{g} \mathrm{kg}^{-1}\right)\end{array}$ & $\begin{array}{l}\text { Positive } \\
\text { Samples }\end{array}$ & $\begin{array}{c}\text { Range } \\
\left(\mu \mathrm{g} \mathrm{kg}^{-1}\right)\end{array}$ & $\begin{array}{l}\text { Positive } \\
\text { Samples }\end{array}$ & $\begin{array}{c}\text { Range } \\
\left(\mu \mathrm{g} \mathrm{kg}^{-1}\right)\end{array}$ & $\begin{array}{l}\text { Positive } \\
\text { Samples }\end{array}$ & $\begin{array}{c}\text { Range } \\
\left(\mu \mathrm{g} \mathrm{kg}^{-1}\right)\end{array}$ \\
\hline AFB1 & 1 & 0.25 & 0 & n.d & 0 & n.d & 0 & n.d & 1 & 0.01 & 0 & n.d & 0 & n.d & 0 & n.d \\
\hline ENA1 & 0 & n.d & 4 & $0.025-0.03$ & 0 & n.d & 0 & n.d & 6 & $0.025-0.03$ & 0 & n.d & 0 & n.d & 0 & n.d \\
\hline ENB & 8 & $0.05-0.09$ & 10 & $0.03-1.2$ & 8 & $0.05-0.3$ & 5 & $0.04-1$ & 13 & $0.09-1$ & 10 & $0.05-1$ & 11 & $0.03-0.09$ & 7 & $0.03-0.07$ \\
\hline ENB1 & 8 & $0.06-0.012$ & 10 & $0.7-1$ & 8 & $0.2-0.6$ & 5 & $0.02-0.6$ & 13 & $0.3-1$ & 10 & $0.4-0.9$ & 11 & $0.2-0.7$ & 7 & $0.2-0.8$ \\
\hline ZEA & 9 & $0.6-1$ & 13 & $0.9-3$ & 3 & $0.5-0.9$ & 8 & 2 & 12 & $1-2.4$ & 5 & $0.5-2$ & 2 & $0.5-0.9$ & 3 & $0.7-1$ \\
\hline DON & 2 & $292-900$ & 10 & $271-830$ & 2 & $479-668$ & 4 & 719-770 & 9 & $16-538$ & 8 & $137-671$ & 3 & $23-138$ & 5 & 232-301 \\
\hline 3-ADON & 1 & 3.03 & 0 & n.d & 0 & n.d & 0 & n.d & 0 & n.d & 0 & n.d & 0 & n.d & 0 & n.d \\
\hline $\mathrm{HT}-2$ & 2 & $7-31$ & 8 & $9-419$ & 3 & $13-19$ & 6 & $4-22$ & 7 & $9-75$ & 4 & $38-88$ & 4 & $3-9$ & 3 & $4-27$ \\
\hline $\mathrm{T}-2$ & 2 & $4-21$ & 3 & $11-33$ & 2 & $13-19$ & 2 & $4-50$ & 2 & $8-48$ & 2 & $9-47$ & 2 & $12-22$ & 2 & $5-33$ \\
\hline
\end{tabular}




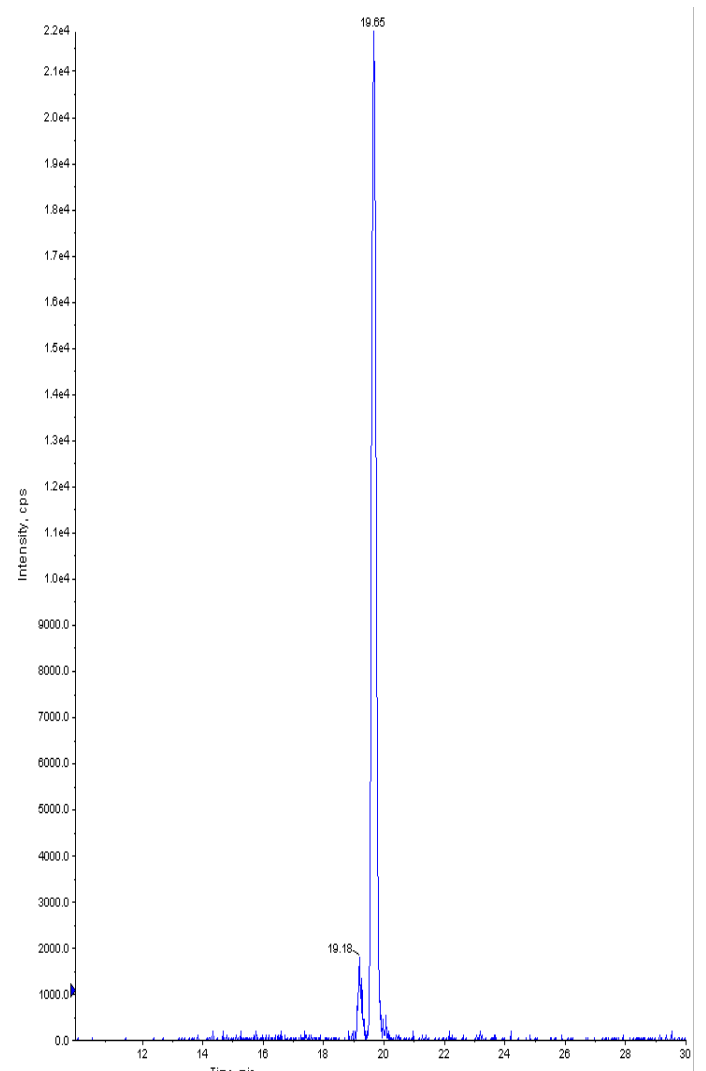

(A)

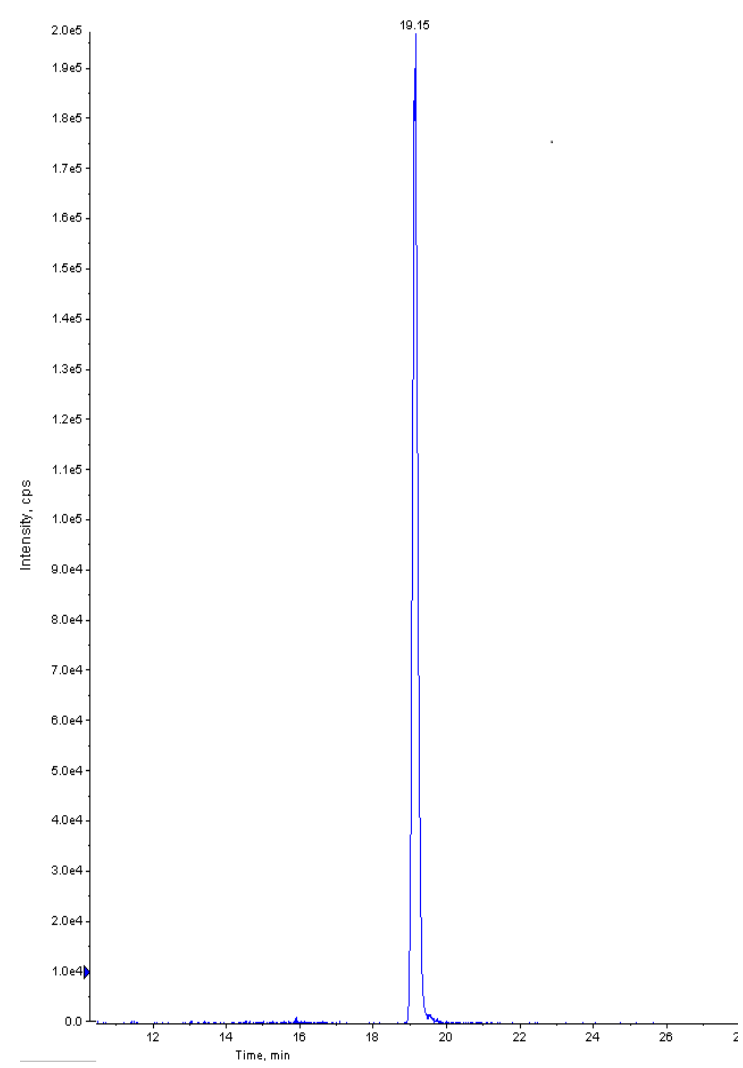

(B)

Figure 1. The chromatograms of two samples of pasta naturally contaminated with (A) enniatin B1 $\left(1 \mu \mathrm{g} \mathrm{kg}^{-1}\right)$ and $(\mathbf{B})$ enniatin B $\left(1.2 \mu \mathrm{g} \mathrm{kg}^{-1}\right)$.

\subsubsection{The Occurrence of DON and 3-ADON}

DON was detected in 43 pasta samples out of 106 total samples (43.5\%) with concentration levels ranging from 16 to $900 \mathrm{\mu g} \mathrm{kg}^{-1}$. There were 22 pasta samples (21\%) contaminated with DON levels ranging from 830 to $900 \mu \mathrm{g} \mathrm{kg}^{-1}$ and exceeding the ML set for DON in cereal products set by the EU regulations $\left(750 \mu \mathrm{g} \mathrm{kg}^{-1}\right)$. In Morocco, there is no ML for DON in pasta; however, a schedule alert of $750 \mu \mathrm{g} \mathrm{kg}^{-1}$ will be applied for this mycotoxin in dry pasta by 2020 according to the Moroccan mycotoxins legislation [13].

The highest DON concentrations in the pasta were found in Agadir, Casablanca, Tanger, and Rabat samples with maximum values of $900,830,770$, and $538 \mu \mathrm{g} \mathrm{kg}^{-1}$, respectively. These four cities are located on the Atlantic Ocean which is characterized by a hot and humid climate that could probably lead to mold contamination and mycotoxin production, especially in coastal areas. Concerning the toxin 3-ADON, only one pasta sample from Agadir was contaminated with a value of $3 \mu \mathrm{g} \mathrm{kg}^{-1}$. In a previous study, it was reported that durum wheat collected in Morocco was contaminated with the toxin DON (11\% of positive samples) with concentrations that ranged from 65 to $1310 \mu \mathrm{g} \mathrm{kg}^{-1}$ [21]. More recently, Blesa et al. reported the presence of DON in wheat grain samples with levels that ranged between 121 and $1480 \mu \mathrm{g} \mathrm{kg}^{-1}$ [22].

Few reports are available worldwide on the presence of DON and derivatives in pasta samples. Indeed, De Nijs et al. reported the presence of DON in four out of 26 dry pasta samples, but none of the samples exceeded the maximum permitted level established by EU countries [8]. In Spain, the presence of DON in 479 cereal-based food products including breakfast cereals, snacks, and pasta showed that DON was the main trichothecene present in positive pasta samples [23]. A study on Italian population exposure to DON through pasta consumption showed that $78.6 \%$ of the 472 samples were contaminated with DON with a mean value of $64.8 \mu \mathrm{g} \mathrm{kg}^{-1}$ [24]. 


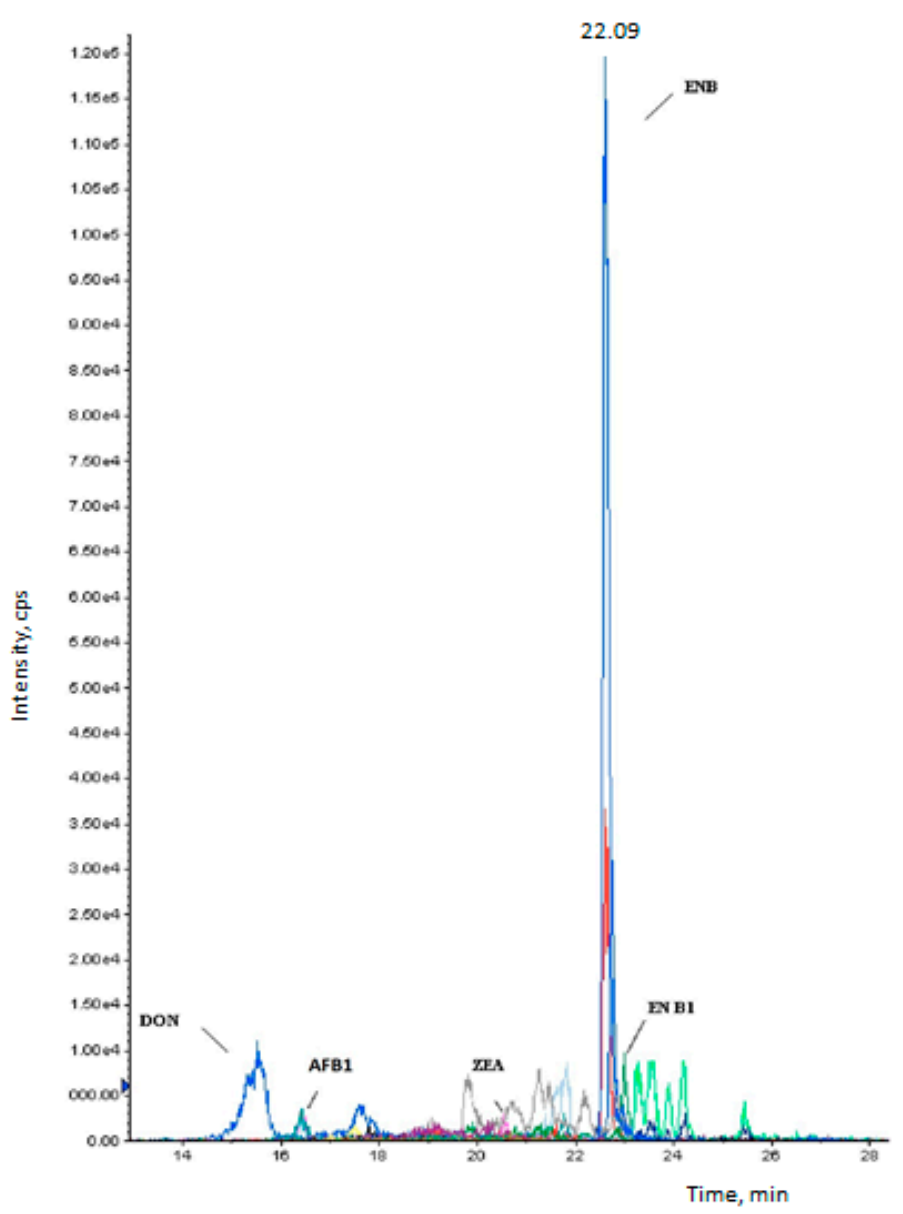

Figure 2. A Chromatogram of a pasta sample with the co-occurrence of five mycotoxins. DON, deoxynivalenol; AFB1, aflatoxin B1; ZEA, zearalenone; ENB1, enniatin B1; ENB, enniatin B.

\subsubsection{The Occurrence of T-2 and HT-2 Toxins}

Concerning the presence of T-2 and HT-2 in pasta, 17 (16\%) and 37 (34.9\%) samples were found contaminated, respectively. Contamination levels varied between 4 and $419 \mu \mathrm{g} \mathrm{kg}^{-1}$ for HT-2, and from 4 to $50 \mu \mathrm{g} \mathrm{kg}^{-1}$ for T-2. Until now, no maximum limits for T-2 or HT-2 have been adopted by Moroccan regulations. According to the analytical results, it could be observed that the incidence of the toxins T-2 and HT-2 in pasta samples is similar to the incidence of ZEA, but it is slightly higher than the incidence of DON. The high contamination of cereal grains with the T-2 and HT-2 toxins (as compared to the DON incidence) was also observed during previous studies in cereals and processed cereals available in Italy and Spain $[25,26]$. Recently, a low contamination level of semolina couscous samples with T-2 and HT-2 was reported [17].

\subsubsection{The Occurrence of Enniatins}

Concerning enniatins, ENB and ENB1 were predominant in positives samples; they were present in 72 out of 106 total pasta samples $(67.9 \%)$ while ENA1 was present in only 10 out of the 106 total samples $(9.4 \%)$ and ENA was not detected in any pasta sample. Regarding their distribution, ENB and ENB1 were present in 13 samples from Rabat, 11 from Kénitra, 10 from Casablanca, 10 from Salé, 8 from Fès, 8 from Agadir, and 7 from Témara. ENA1 was found in 6 samples from Rabat and 4 from Casablanca. In the positive samples, ENB concentrations ranged from 0.03 to $1.2 \mu \mathrm{g} \mathrm{kg}^{-1}$, ENB1 concentrations varied from 0.012 to $1 \mu \mathrm{g} \mathrm{kg}^{-1}$, and ENA1 was detected up to $0.03 \mu \mathrm{g} \mathrm{kg}^{-1}$. Recently, the presence of enniatins in pasta has been investigated. Indeed, two studies from Spain showed the occurrence of enniatins in different types of pasta. The first one reported the presence of 
enniatins in dry pasta where ENA was predominant [7]. In the second study, enniatins were found in all the analyzed samples of organic dry pasta, conventional dry pasta, and fresh pasta and ENB1 was predominant [27]. Even though enniatins were found to be frequent in the samples investigated herein and the percentage of positive samples was quite high (case of ENB and ENB1), the levels of enniatins found are lower compared to previous studies [27]. The extraction method used in our study showed a high sensitivity for Fusarium toxins specifically for ENA, ENA1, and ENB as compared to other studies in pasta. Indeed, the recoveries obtained were higher than $80 \%$.

In the Mediterranean area, previous studies have shown the presence of enniatins in several cereal commodities, especially from Morocco. Indeed, the presence of Fusarium toxins was already reported in wheat grain with levels that ranged between 2.5 and $2570 \mu \mathrm{g} \mathrm{kg}^{-1}$ [22]. A previous study has shown also that breakfast cereals and infant cereals were contaminated with ENs, particularly ENA1 [28], while Sifou et al. reported the presence of ENs in rice samples with a contamination frequency that reached $50 \%$ of the total analyzed samples [29]. More recently, the presence of enniatins (ENB, ENB1, and ENA1) in couscous semolina from Morocco was also reported [17].

\subsubsection{Multi-Mycotoxin Occurrence in Pasta}

From different toxicological studies, exposure to various mycotoxins together may lead to additive, and even synergistic toxic effects [30]. In the present survey, the multi-presence of several mycotoxins in the same pasta sample was observed. Indeed, among the positive samples, $73.6 \%(78 / 106)$ were found to be contaminated with at least one mycotoxin. A total of $39.6 \%$ of positive samples $(42 / 106)$ were found contaminated simultaneously with 2 mycotoxins, while six mycotoxins co-occurred in only one pasta sample. In this work, the most frequent mycotoxins found in the pasta samples were enniatins (ENB and ENB1), ZEA, DON, T-2, and HT-2.

The multi-mycotoxin occurrence in cereals and derivatives has been surveyed in some Mediterranean countries. In wheat grain from Morocco, $51 \%$ of samples contained more than one mycotoxin [22]. While in Spain, it was reported that $65 \%$ of cereal derivatives samples showed a contamination by at least one mycotoxin [18]. Recently, a study performed in Italy showed that $80 \%$ of 27 pasta samples were contaminated with six to ten mycotoxins [31]. In Morocco, the co-occurrence of mycotoxins in couscous samples showed that ninety-six (96) out of ninety-eight (98) total samples $(97.9 \%)$ were contaminated by at least one mycotoxin and that ENB and EB1 showed the highest incidence [17].

\subsection{Risk Assessment}

Risk assessment related to the dietary exposure of mycotoxins in pasta was calculated by estimating the PDIs for DON and derivatives (DON + 3-ADON + 15-ADON), ZEA, and T-2 + HT-2 . However, as the Joint FAO/WHO Expert Committee on Food Additives has not established provisional maximum tolerable daily intakes (PMTDI) for Enniatins [32], PDIs were not estimated in this study for this kind of mycotoxins. It should be indicated that as there are no official data on pasta intake in Morocco, the PDIs estimated from pasta consumption in this investigation is only for orientation purposes. In 2004, according to the cereal professional association's surveys, the consumption of pasta was estimated to be about $2 \mathrm{~kg} /$ person/year, however, since the consumption of pasta in the country is in escalation, the estimated value is $4.5 \mathrm{~kg} /$ person/year in 2016 [33].

The risk characterizations of these mycotoxins have been calculated using the previous equation based on the probable daily intakes of the Moroccan population, as shown in Table 4. The dietary exposure values through the consumption of pasta were estimated to be $0.073 \mu \mathrm{g} \mathrm{kg}^{-1} \mathrm{bw} \mathrm{day}^{-1}$ for the sum of (DON + 3-ADON + 15-ADON), 0.097 for the sum of (T-2 + HT-2), and 0.0002 for ZEA. Theses intakes values are equivalent to $0.08 \%, 7.3 \%$, and $97 \%$ of the TDIs of ZEA, the sum of (DON $+3-\mathrm{ADON}+15-\mathrm{ADON})$, and the sum of (T-2 + HT-2) respectively. As shown, the highest PDI (97\%) was obtained from the sum of (T-2 + HT-2). However, all estimated PDIs are below the TDIs set by $\mathrm{FAO} / \mathrm{WHO}$ expert JECFA committees. Since the consumption of pasta is increasing in the country, so 
the presence of mycotoxins should be controlled because the exposure will get higher and might pose a health risk for the average consumer. High attention should be devoted to the exposure of regular consumers, such as children. For comparison, a study performed in Italy concerning the exposure assessment to DON through pasta consumption of different population groups in different scenarios concluded that no health concern was assessed for all consumers, the exposure being far below the TDI of $1 \mu \mathrm{g} \mathrm{kg}^{-1} \mathrm{bw} \mathrm{day}^{-1}$ [24].

Table 4. The estimated exposure of the studied mycotoxins.

\begin{tabular}{|c|c|c|c|c|c|}
\hline Mycotoxin & $\underset{\left(\mu \mathrm{gg}^{-1} \text { pasta }\right)}{\mathrm{Cm}}$ & 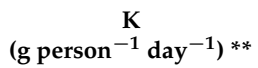 & $\begin{array}{c}\text { PDIm } \\
\left(\mu \mathrm{kg}^{-1} \mathrm{bw} \mathrm{day}^{-1}\right)^{* * *}\end{array}$ & $\begin{array}{c}\text { TDI } \\
\left(\mu \mathrm{kg}^{-1} \text { bw day }\right. \\
\end{array}$ & $\begin{array}{c}\% \\
\text { TDI }\end{array}$ \\
\hline $\begin{array}{c}\mathrm{DON}+3-\mathrm{ADON}+ \\
15-\mathrm{ADON}\end{array}$ & 440.95 & 11.6 & 0.073 & 1 & 7.3 \\
\hline $\mathrm{HT}-2+\mathrm{T} 2$ & 58.65 & 11.6 & 0.097 & 0.1 & 97 \\
\hline ZEA & 1.20 & 11.6 & 0.0002 & 0.25 & 0.08 \\
\hline
\end{tabular}

* Cm: Mean content of a mycotoxin ( $\mu \mathrm{g} \mathrm{kg}^{-1}$ pasta). ${ }^{* *} \mathrm{~K}$ : Average consumption of the commodity (g person ${ }^{-1}$ day $\left.^{-1}\right)$. ${ }^{* *}$ PDIm: Probable daily intake $\left(\mu \mathrm{g} \mathrm{kg}{ }^{-1}\right.$ bw day $\left.{ }^{-1}\right)$ for each mycotoxin. TDI: Tolerable daily intake.

\section{Conclusions}

In this paper, a multi-mycotoxin method analysis has been validated and applied to 106 pasta samples from Morocco to evaluate the presence of twenty mycotoxins. Most of the samples (93.4\%) were contaminated with at least one mycotoxin. ENB and ENB1 showed the highest incidence followed by ZEA, DON, HT-2, and T-2. The multi-occurrence of mycotoxins in pasta samples was also found. Some samples exceeded the ML established by EU legislation, especially for DON. The risk of some of the mycotoxins studied was assessed and pasta consumption does not raise any toxicological concern in the general population because of the low mycotoxin exposure. However, some population groups (children and/or adolescent) could be exposed to a higher risk since they are considered more frequent consumers of pasta in the country.

\section{Materials and Methods}

\subsection{Chemicals and Reagents}

HPLC grade solvents (hexane, methanol $(\mathrm{MeOH})$ and acetonitrile $(\mathrm{AcN}))$ were purchased from Merck (Darmstadt, Germany). Deionized water ( $<18 \mathrm{M} \Omega \mathrm{cm}$ resistivity) was obtained in the laboratory using a Milli-Q SP Reagent Water System (Millipore, Bedford, MA, USA).

Standards of mycotoxins including (aflatoxins (B1, B2, G1 and G2); enniatins (A, A1, B and B1); fumonisins (B1 and B2); nivalenol (NIV); deoxynivalenol (DON); 15-acetyldeoxynivalenol (15-ADON); 3-acetyldeoxynivalenol (3-ADON); zearalenone (ZEA); beauvericin (BEA); fusarenon X (FUS-X)) were purchased from Sigma Aldrich (Madrid, Spain). The T-2 and HT-2 toxins were provided from BiopureReferenzsubstanzenGmBH (Tulln, Austria). Finally, fumonisin B3 was provided by the Research Program "PROMEC" (Tygerberg) in South Africa. All stock solutions of mycotoxins standards were stored in glass-stoppered bottles in darkness at $-20{ }^{\circ} \mathrm{C}$ until the final analysis. For the derivatization, the reagent composed of BSA (N,O-bis (trimethylsilyl) acetamide)/TMCS (trimethylchlorosilane)/TMSI (N-trimethylsilyimidazole) (3:2:3) was obtained from Supelco (Bellefonte, PA, USA).

\subsection{Sample Collection}

One hundred and six (106) pasta samples from different commercial brands were randomly purchased in retail shops and supermarkets from eight (8) cities in Morocco during the 2016 and 2017 : Agadir $(n=11)$, Casablanca $(n=17)$, Fes $(n=11)$, Tanger $(n=10)$, Rabat $(n=20)$, Salé $(n=12)$, Kénitra $(n=15)$, and Témara $(n=10)$. The sample size of each sample was at least $2 \mathrm{~kg}$. All samples were ground at $<0.75 \mathrm{~mm}$, divided into subsamples of $200 \mathrm{~g}$, sealed in plastic bags, and stored at $4{ }^{\circ} \mathrm{C}$ until mycotoxin analysis. 


\subsection{Sample Preparation}

The pasta sample was prepared and analyzed with an in-house validated method. Briefly, $5 \mathrm{~g}$ of pasta sample was weighed into a centrifuge tube of $50 \mathrm{~mL}$. Ten (10) $\mathrm{mL}$ of water milliQ and $10 \mathrm{~mL}$ of AcN were added to the sample. The tube was vortexed for $5 \mathrm{~min}$ and shacked at $300 \mathrm{rpm}$ for $30 \mathrm{~min}$. Then, $1 \mathrm{~g}$ of $\mathrm{NaCl}$ and $4 \mathrm{~g}$ of $\mathrm{MgSO} 4$ were added and the tube was vortexed for $5 \mathrm{~min}$. The tube was centrifuged at $4500 \mathrm{rpm}$ for $10 \mathrm{~min}$ at $20^{\circ} \mathrm{C}$. The upper solution was evaporated to dryness under a nitrogen stream at $40{ }^{\circ} \mathrm{C}$. Finally, the extract was dissolved with $1 \mathrm{~mL}$ of water/methanol (50/50, $v / v$ ). Before analysis, each sample was filtrated through a $0.22 \mu \mathrm{m}$ PTFE filter and an aliquot of $500 \mu \mathrm{L}$ was injected to the LC/MS/MS system, while the other aliquot was used for derivatization and GC/MS/MS analysis.

\subsection{GC-QqQ-MS/MS Equipment}

Prior to the GC/MS/MS analysis, the extracts were derivatized before their injection into the apparatus. For this, the extracts were evaporated to dryness under nitrogen, treated with $50 \mu \mathrm{L}$ of BSA + TMCS + TMSI (3:2:3) and left for $30 \mathrm{~min}$ at room temperature. The sample was then diluted with hexane to obtain a volume of $250 \mu \mathrm{L}$ and mixed with a vortex thoroughly for $30 \mathrm{~s}$. Finally, the sample was washed with $1 \mathrm{~mL}$ of phosphate buffer $(60 \mathrm{mM}, \mathrm{pH} 7)$ and the clear hexane layer was transferred into a vial for the analysis.

For mycotoxins determination, a GC apparatus system (Agilent 7890A, Agilent Technologies, Palo Alto, CA, USA) coupled with a triple quadruple mass spectrometer (Agilent 7000A) with an inert electron-impact ion source and an auto-sampler (Agilent 7693) was used. The mass spectrometer was operated in electron impact ionization (EI, $70 \mathrm{eV}$ ). Data were acquired and processed using the Agilent MassHunter version B.04.00 software (Palo Alto, CA, USA).

After derivatization, $1 \mu \mathrm{L}$ of sample extract was injected at $250{ }^{\circ} \mathrm{C}$ in programmable temperature vaporization (PTV). Then, analytes were separated on a capillary column (HP-5MS $30 \mathrm{~m} \times 0.25 \mathrm{~mm} \times$ $0.25 \mu \mathrm{m}$ ) by using helium as the carrier gas with a fixed pressure value of $20.3 \mathrm{psi}$. The temperature was programmed (initially at $80^{\circ} \mathrm{C}$, and increased to $245^{\circ} \mathrm{C}$, at $60^{\circ} \mathrm{C} \mathrm{min}{ }^{-1}$ ). The temperature was then increased to $260^{\circ} \mathrm{C}$ after a $3 \mathrm{~min}$ hold time $\left(\right.$ at $3{ }^{\circ} \mathrm{C} \mathrm{min}{ }^{-1}$ ) and finally to $270{ }^{\circ} \mathrm{C}$ (at $10{ }^{\circ} \mathrm{C} \mathrm{min}{ }^{-1}$ ) and then held for $10 \mathrm{~min}$. Analytes were eluted within $12 \mathrm{~min}$, reaching the requirement for a high throughput determination.

For quantification purposes, the criteria set by the EC were achieved [34]. Indeed, for each analyte, two selected reaction monitoring (SRM) transitions for each compound were required. The most intense SRM transition was selected for quantification purposes. The specific MS/MS parameters for each mycotoxin were $m / z$ 347/157-347/ 185 for HT-2, $m / z$ 350/259-350/229 for T-2, $m / z$ 289/73-379/73 for NIV, $m / z$ 392/259-407/197 for DON, $m / z$ 392/287-467/147 for 3-ADON, $m / z$ 392/217-392/184 for 15-ADON, and $m / z$ 450/260-450/245 for FUS-X.

\subsection{LC/MS/MS Equipment}

For LC/MS/MS analysis of mycotoxins, An LC triple quadruple mass spectrometer from Micromass (Manchester, UK) was used. The apparatus is equipped with an LC Alliance 2695 system (Waters, Milford, MA, USA), a quaternary pump, an autosampler, a pneumatically assisted electrospray probe, and a Z-spray interface. Additionally, the Mass Lynx NT software version 4.1 was used (Waters, Milford, MA, USA).

For the separation, a Gemini-NX C18 analytical column $(150 \times 2.0 \mathrm{~mm}$ I.D, $3.0 \mu \mathrm{m})$ supplied by Phenomenex (Barcelona, Spain) was used, the column was preceded by a cartridge C18. The mobile phase consisted of a mixture of solvents I ( $5 \mathrm{mM}$ ammonium formate and $0.1 \%$ formic acid in methanol) and II ( $5 \mathrm{mM}$ ammonium formate and $0.1 \%$ formic acid in water) at a flow rate of $0.25 \mathrm{~mL} / \mathrm{min}$. The elution gradient was established initially with $10 \%$ eluent B, increased to $80 \%$ in $1.5 \mathrm{~min}$, then kept 
constant from 1.5 to $4 \mathrm{~min}$, increased to $90 \%$ from 4 to $10 \mathrm{~min}$, increased again to $100 \%$ from 10 to $14 \mathrm{~min}$, and finally returned to the initial conditions and equilibrated during $10 \mathrm{~min}$.

Analyses were performed in the positive ion mode. The main MS parameters were optimized and finally set as follows: nebulizer gas (GS1), 55 psi; auxiliary gas (GS2), 50 psi; curtain gas (CUR) 15 psi; capillary temperature $550{ }^{\circ} \mathrm{C}$; ion spray voltage (IS) $5500 \mathrm{~V}$. Nitrogen was used as the collision gas. The precursor-to-product ion transitions were $m / z$ 313.3/241.3-284.9 for AFB1, $m / z$ 315.3/259.0-288.4 for AFB2, $m / z$ 329.7/243.3-311.1 for AFG1, $m / z$ 331.1/313.0-245.0 for AFG2, $m / z$ 722.4/334.3-352.3 for FB1, $m / z$ 706.4/336.2-318.3 for FB2, $m / z$ 706.4/336.2-318.3 for FB3, $m / z$ 319.0/282.9-301.0 for ZEA $m / z$ 657.3/196.1-214.0 for ENB, $m / z$ 671.2/214.2-228.1 for ENB1, $m / z$ 699.4/210.2-228.2 for ENA, $m / z$ 685.4/214.2-210.2 for ENA1, and $m / z$ 801.2/784.1-244.1 for BEA.

\subsection{Method Validation}

The method validation was carried out inclusive of the determination of accuracy, repeatability, sensitivity, and linearity. Recoveries were calculated at three different spiked levels 25, 50 and $100 \mu \mathrm{g} \mathrm{kg}{ }^{-1}$ with three replicates $(n=3)$. The matrix effect (ME\%) for each mycotoxin was determined according to the formula defined as the percentage of the matrix-matched calibration slope divided by the slope of the standard calibration and multiplied by 100. Matrix-matched calibration curves were used for the quantification in pasta. Accuracy was calculated through recovery studies, the spiked samples were left to stand for $2 \mathrm{~h}$ at ambient temperature before the extraction and three replicates were used for each spiking concentration. Precision was estimated by calculating the relative standard deviation (RSD) using the results obtained during the same day, and on three different days by the repeated analysis at the three spiked concentrations. Sensitivity was evaluated by the LOD and the LOQ, which were estimated for a signal-to-noise ratio $(\mathrm{S} / \mathrm{N}) \geq 3$ and $\geq 10$, respectively. Spiking was performed in 5-fold at two levels (10 and $\left.100 \mu \mathrm{g} \mathrm{kg}^{-1}\right)$. Together with the control samples, the fortified samples were processed using the extraction procedure described above. Aliquots of the control extracts were used to prepare the matrix-matched calibration using six concentration levels, between LOQ and 100 times LOQ. The same calibration standards were also prepared in water-methanol $(50: 50 v / v)$.

\subsection{Mycotoxins Dietary Intake Calculation}

For risk assessment of the studied mycotoxins, we have followed the deterministic approach. The exposure was estimated by the probable daily intake (PDI) which combines the average amount of mycotoxins found in pasta with the food consumption estimation in Moroccan adult populations. According to AMIPAC, the Moroccan consumption of pasta was approximately estimated at $2 \mathrm{~kg}$ per person per year [33]. The PDI ( $\mu \mathrm{g} \mathrm{kg}{ }^{-1}$ per body weight (bw)/day) of each mycotoxin was calculated as indicated [18] in the following formula (A):

$$
\mathrm{PDI}=(\mathrm{M} \times \mathrm{C}) / \mathrm{bw}
$$

" $\mathrm{M}$ " is the mean level $\left(\mu \mathrm{g} \mathrm{kg}^{-1}\right)$ of each mycotoxin; " $\mathrm{C}$ " is the average consumption $\left(\mathrm{g} \mathrm{day}^{-1}\right)$ of pasta; and bw is the body weight used for the adult population (estimated at $70 \mathrm{~kg}$ ). For the risk characterization of mycotoxins (\% of relevant TDI), it was obtained by dividing the PDI previously calculated in the formula (A) with the tolerable daily intake (TDI) $\left(\mu \mathrm{g} \mathrm{kg}^{-1} \mathrm{bw} \mathrm{day}^{-1}\right)$ as indicated in the following formula (B):

$$
\% \mathrm{TDI}=(\mathrm{PDI} / \mathrm{TDI}) \times 100
$$

According to the safety guidelines of the $\mathrm{FAO} / \mathrm{WHO}$ joint committees established for mycotoxins, the TDI values were $0.25 \mu \mathrm{g} \mathrm{kg}^{-1} \mathrm{bw}$ day $^{-1}$ for ZEA, $1.2 \mu \mathrm{g} \mathrm{kg}^{-1} \mathrm{bw} \mathrm{day}^{-1}$ for NIV, $0.1 \mu \mathrm{g} \mathrm{kg}^{-1} \mathrm{bw}$ day $^{-1}$ for the sum of T-2 to HT-2 and provisional maximum TDI (PMTDI) for fumonisins of $2 \mu \mathrm{g} \mathrm{kg}^{-1} \mathrm{bw}$ day $^{-1}$. The provisional maximum tolerable daily intakes (PMTDI) of DON + 3-ADON + 15-ADON was set at $1 \mu \mathrm{g} \mathrm{kg}^{-1} \mathrm{bw} \mathrm{day}^{-1}$ [35]. It should be indicated that the 
FAO/WHO joint expert groups have not specified the TDI for AFs since no safe limit can be set for confirmed carcinogenic chemicals. For this, FAO/WHO experts recommended that exposure through food should be reduced to As Low As Reasonably Achievable (ALARA). For Enniatins, BEA, and DAS, no PDI or PMTDI data are still fixed until now.

Author Contributions: M.F.-F. and J.M. conceived and designed the experiments; Y.B and H.B. performed the experiments; L.M., M.R. and A.Z. analyzed the data.

Funding: The research was supported by Conselleria de Educación, Investigación, Cultura y Deporte (AICO/2018/199) and the Ministry of Economy and Competitiveness (AGL2016-77610-R).

Acknowledgments: This research was supported by Conselleria de Educación, Investigación, Cultura y Deporte (AICO/2018/199) and the Ministry of Economy and Competitiveness (AGL2016-77610-R). Y.B. is most grateful to the University of Valencia (Spain) for the Grant given (Becas Jovenes Investigadores).

Conflicts of Interest: The authors declare that there are no conflict of interest relevant to this article.

\section{References}

1. International Pasta Organisation. The World Pasta Industry Status Report 2013. Available online: http://www. internationalpasta.org/resources/World\%20Pasta\%20Industry\%20Survey/IPOstatreport2014low.pdf (accessed on 15 September 2018).

2. Plavšić, D.V.; Psodorov, Đ.B.; Kalenjuk, B.M.; Tešanović, D.V.; Šarić, L.Ć.; Čabarkapa, I.S.; Filipović, J.S. Comparison of microbiological safety of pasta and pasta related products depending on the conditions of production. Food Feed Res. 2010, 37, 51-58.

3. Tantaoui-Elaraki, A.; Riba, A.; Oueslati, S.; Zinedine, A. Toxigenic fungi and mycotoxin occurrence and prevention in food and feed in northern Africa-A review. World Mycotoxin J. 2018, 11, 385-400. [CrossRef]

4. Van Egmond, H.P.; Schothorst, R.C.; Jonker, M.A. Regulations relating to mycotoxins in food. Anal. Bioanal. Chem. 2007, 389, 147-157. [CrossRef] [PubMed]

5. IARC. Monograph on the Evaluation of Carcinogenic Risk to Humans; World Health Organization: Lyon, France, 2002; Volume 82.

6. Gareis, M. Collection of occurrence data of Fusarium toxins in food and assessment of dietary intake by the population of EU member states. Report of Experts Participating in SCOOP Task 3.2. 10-Part A: Trichothecene. 2003, pp. 13-235. Available online: https:/ /ec.europa.eu/food/sites/food/files/safety/docs/ Cs_contaminants_catalogue_fusarium_task3210.pdf (accessed on 15 September 2018).

7. Ficheux, A.S.; Sibiril, Y.; Parent-Massin, D. Co-exposure of Fusarium mycotoxins: In vitro myelotoxicity assessment on human hematopoietic progenitors. Toxicon 2012, 60, 1171-1179. [CrossRef] [PubMed]

8. De Nijs, M.; Van den Top, H.; De Stoppelaar, J.; Lopez, P.; Mol, H. Fate of enniatins and deoxynivalenol during pasta cooking. Food Chem. 2016, 213, 763-767. [CrossRef] [PubMed]

9. Serrano, A.B.; Font, G.; Mañes, J.; Ferrer, E. Effects of technological processes on enniatin levels in pasta. J. Sci. Food Agric. 2016, 96, 1756-1763. [CrossRef] [PubMed]

10. Ibáñez-Vea, M.; González-Peñas, E.; Lizarraga, E.; de Cerain, A.L. Co-occurrence of mycotoxins in Spanish barley: A statistical overview. Food Control 2012, 28, 295-298. [CrossRef]

11. EC. Commission Regulation (EC) No 401/2006 of 23 February 2006 laying down the methods of sampling and analysis for the official control of the levels of mycotoxins in foodstuffs. Off. J. Eur. Union 2006, 70, 12-34.

12. EC. Commission Regulation (EC) No. 1126/2007 of 28 September 2007 amending regulation (EC) No $1881 / 2006$ setting maximum levels for certain contaminants in foodstuffs as regards Fusarium toxins in maize and maize products. Off. J. Eur. Union 2007, 255, 1-4.

13. BO. Arrêté Conjoint du Ministre de L'agriculture et de la Pêche Maritime et du Ministre de la Santé n ${ }^{\circ} 643-16$ du 23 Chaabane 1437 (30 Mai 2016) Fixant les Limites Maximales Autorisées des Contaminants dans les Produits Primaires et les Produits Alimentaires. Available online: http:/ /www.onssa.gov.ma/fr/images / reglementation/transversale/ARR.1643-16.FR.pdf (accessed on 15 September 2018). 
14. Zinedine, A.; Mañes, J. Occurrence and legislation of mycotoxins in food and feed from Morocco. Food Control 2009, 20, 334-344. [CrossRef]

15. Azaiez, I.; Giusti, F.; Sagratini, G.; Mañes, J.; Fernández-Franzón, M. Multi-mycotoxins analysis in dried fruit by LC/MS/MS and a modified QuEChERS procedure. Food Anal. Methods 2014, 7, 935-945. [CrossRef]

16. Arroyo-Manzanares, N.; Huertas-Pérez, J.F.; García-Campaña, A.M.; Gámiz-Gracia, L. Review of Sample Treatments and the State-of-the-art of Analytical Techniques for Mycotoxins in Food. In Analysis of Food Toxins and Toxicants; Wong, Y.-C., Lewis, R.J., Eds.; John Wiley \& Sons, Ltd.: New York, NY, USA, 2017; pp. 51-102.

17. Zinedine, A.; Fernández-Franzón, M.; Mañes, J.; Manyes, L. Multi-mycotoxin contamination of couscous semolina commercialized in Morocco. Food Chem. 2017, 214, 440-446. [CrossRef] [PubMed]

18. Rodríguez-Carrasco, Y.; Berrada, H.; Font, G.; Mañes, J. Multi-mycotoxin analysis in wheat semolina using an acetonitrile-based extraction procedure and gas chromatography-tandem mass spectrometry. J. Chromatogr. A 2012, 1270, 28-40. [CrossRef] [PubMed]

19. Schollenberger, M.; Müller, H.-M.; Rüfle, M.; Drochner, W. Natural occurrence of 16 Fusarium toxins in edible oil marketed in Germany. Food Control 2008, 19, 475-482. [CrossRef]

20. El-Desouky, T.; Naguib, K. Occurrence of zearalenone contamination in some cereals in Egypt. J. Agroaliment. Process. Technol. 2013, 19, 445-450.

21. Ennouari, A.; Sanchis, V.; Marín, S.; Rahouti, M.; Zinedine, A. Occurrence of deoxynivalenol in durum wheat from Morocco. Food Control 2013, 32, 115-118. [CrossRef]

22. Blesa, J.; Moltó, J.-C.; El Akhdari, S.; Mañes, J.; Zinedine, A. Simultaneous determination of Fusarium mycotoxins in wheat grain from Morocco by liquid chromatography coupled to triple quadrupole mass spectrometry. Food Control 2014, 46, 1-5. [CrossRef]

23. Cano-Sancho, G.; Valle-Algarra, F.; Jiménez, M.; Burdaspal, P.; Legarda, T.; Ramos, A.; Sanchis, V.; Marín, S. Presence of trichothecenes and co-occurrence in cereal-based food from Catalonia (Spain). Food Control 2011, 22, 490-495. [CrossRef]

24. Brera, C.; Bertazzoni, V.; Debegnach, F.; Gregori, E.; Prantera, E.; De Santis, B. Exposure assessment for italian population groups to deoxynivalenol deriving from pasta consumption. Toxins 2013, 5, 2293-2309. [CrossRef] [PubMed]

25. Rodríguez-Carrasco, Y.; Ruiz, M.-J.; Font, G.; Berrada, H. Exposure estimates to Fusarium mycotoxins through cereals intake. Chemosphere 2013, 93, 2297-2303. [CrossRef] [PubMed]

26. Juan, C.; Ritieni, A.; Mañes, J. Occurrence of Fusarium mycotoxins in Italian cereal and cereal products from organic farming. Food Chem. 2013, 141, 1747-1755. [CrossRef] [PubMed]

27. Serrano, A.; Font, G.; Mañes, J.; Ferrer, E. Emerging Fusarium mycotoxins in organic and conventional pasta collected in Spain. Food Chem. Toxicol. 2013, 51, 259-266. [CrossRef] [PubMed]

28. Mahnine, N.; Meca, G.; Elabidi, A.; Fekhaoui, M.; Saoiabi, A.; Font, G.; Mañes, J.; Zinedine, A. Further data on the levels of emerging Fusarium mycotoxins enniatins (A, A1, B, B1), beauvericin and fusaproliferin in breakfast and infant cereals from Morocco. Food Chem. 2011, 124, 481-485. [CrossRef]

29. Sifou, A.; Meca, G.; Serrano, A.B.; Mahnine, N.; El Abidi, A.; Mañes, J.; El Azzouzi, M.; Zinedine, A. First report on the presence of emerging Fusarium mycotoxins enniatins (A, A1, B, B1), beauvericin and fusaproliferin in rice on the Moroccan retail markets. Food Control 2011, 22, 1826-1830. [CrossRef]

30. Lu, H.; Fernández-Franzón, M.; Font, G.; Ruiz, M. Toxicity evaluation of individual and mixed enniatins using an in vitro method with CHO-K1 cells. Toxicol. In Vitro 2013, 27, 672-680. [CrossRef] [PubMed]

31. Tolosa, J.; Graziani, G.; Gaspari, A.; Chianese, D.; Ferrer, E.; Mañes, J.; Ritieni, A. Multi-mycotoxin analysis in durum wheat pasta by liquid chromatography coupled to quadrupole orbitrap mass spectrometry. Toxins 2017, 9, 59. [CrossRef] [PubMed]

32. JECFA. Joint FAO/WHO expert committee on food additives. In Safety Evaluation of Certain Mycotoxins in Food; Food and Agriculture Organization: Rome, Italy, 2001; pp. 281-320.

33. AMIPAC. Diagnostic project of the competitiveness of the industrial sector of pasta and couscous in Morocco. Daniel Juge. February 2004. Available online: http:/ / www.fncl.ma (accessed on 10 August 2018). 
34. European Commission. Guidance Document on Analytical Quality Control and Method Validation Procedures for Pesticides Residues Analysis in Food and Feed; SANTE/11945/2015; European Commission: Brussels, Belgium, 2015; pp. 1-42.

35. FAO/WHO. Summary Report of the 72nd Meeting of the Joint FAO/WHO Expert Committee on Food Additives (JECFA). 2010. Available online: http://www.fao.org/3/a-at868e.pdf (accessed on 15 September 2018). 